\title{
Н.Н. Макарова
}

\section{СБОРНИК ДОКУМЕНТОВ «МАГНИТОГОРСК ДОВОЕННЫЙ» КАК ИСТОЧНИК ДЛЯ ИЗУЧЕНИЯ ИСТОРИИ ИНДУСТРИАЛИЗАЦИИ (ОПЫТ РАБОТЫ С ПРОГРАММОЙ МАХQDА)}

\begin{abstract}
В статье рассматриваются функциональные возможности программы MAXQDA в исторических исследованиях. Описан опыт анализа материалов сборника документов «Магнитогорск довоенный», проведенного с помощью компьютерной программы MAXQDA. Использование этой программы, как одной из ведущих в области комплексного анализа текста, позволило получить точные данные о характерных чертах развития г. Магнитогорск в период форсированной индустриализации (1930-1940 гг.) по годам, связях между содержанием статей и некоторые общие сведения о языке публикаций в эти годы.

Ключевые слова: индустриализация; Магнитогорск; анализ текста; контент-анализ; первые пятилетки; MAXQDA.
\end{abstract}

Цифровой мир в настоящее время перестал быть утопичным будущим, технологии цифровой цивилизации окружают современного человека. Естественно, что ученые наиболее тесно соприкасаются с достижениями информационных технологий. Даже историческая наука, которая традиционно опирается на материалы архивных фондов и библиотечные коллекции, довольно активно использует новейшие достижения в области информационных технологий. Сегодня «цифровая история», или «digital history», становится профессиональной реальностью. По справедливой оценке А.Ю. Володина, говоря о цифровой истории, следует иметь ввиду не только репрезентацию истории, но и новые эвристические подходы к поиску исторических источников, методические подходы к исторической критике и пр. [1] Начало цифровой истории было положено в 1997 г. американскими исследователями Э. Айерсом и У. Томасом, основавшими Вирджинский центр цифровой истории (Virginia Center for Digital History, VCDH) при университете Вирджинии. Первые работы, посвященные осмыслению цифровой истории, были написаны на рубеже XX-XXI вв. [2, 3]. В России часто используется термин, предложенный Л.И. Бородкиным, - «историческая информатика». По сути «историческая информатика» и «цифровая история» представляют собой междисциплинарную область исследований исторической науки и прикладной информатики. В основе исторической информатики лежат совокупность теоретических и прикладных знаний, необходимых для создания, обработки и анализа цифровых версий исторических источников и электронных ресурсов, а также развитие методов сбора, хранения, обработки и передачи исторической информации с использованием компьютерных технологий [4].

В целом теоретическое наследие «digital history» в России и за рубежом довольно разнообразно. Подробный анализ основных этапов развития исторической информатики предложен в работах Л.И. Бородкина [57], а также в серии статей Г.В. Можаевой, М. Таллера,
И.М. Гарсковой и зарубежных исследователей П. Алховена, П. Доорна, О. Боонстра, Л. Бреуре [8-14]. Авторы сконцентрировали внимание на дискуссионных вопросах в области цифровой истории, в частности в отношении форм и инфраструктуры цифровой гуманитаристики [9] и возможных перспектив направления исследований [10]. Новейшие труды в «Digital Humanities» проанализированы коллективом авторов статьи «Конференция Digital Humanities 2016: перспективы и вызовы для развития сообества гуманитарной информатики» [15]. Она отражает состояние цифровых гуманитарных исследований в контексте проблем конференции «Digital Humanities 2016»- ежегодной конференции Альянса организаций цифровых гуманитарных наук (ADHO). Авторам удалось не только представить основные этапы развития конференции, но и показать обзор избранных докладов. Однако опыт практического применения конкретных информационных ресурсов в настоящее время представлен не слишком широко.

Часть исследований, демонстрирующих методику работы и конкретные результаты, к настоящему моменту устарела, так как информационные технологии постоянно развиваются [16-19]. Новейшие исследования представлены, в частности, монографией Д.И. Жеребятьева о применении трехмерного компьютерного моделирования в процессе реконструкции монастырей [20]. Значимой является также монография Л.И. Бородкина «Моделирование исторических процессов: от реконструкции реальности к анализу альтернатив», в которой отдельные главы посвящены моделированию социальной мобильности в российском социуме XIX начала XX в. [21]. В статье Н.С. Гусевой проанализировано применение математических методов в разработках по аграрной истории России в отражении историографии [22]. Отдельного внимания заслуживают труды, посвященные теоретическим и методологическим вопросам использования контент-анализа, а также особенностям технической обработки информации и 
сочетания контент-анализа с иными методиками исследования. В изучении контент-анализа можно выделить несколько этапов. Первый этап охватывает период с конца XIX в. по 1930-е гг. (Б. Мэттью, А. Тенни, Д. Спиид, Д. Уипкинс, Ж. Кайзер, Г. Лассуэлл, Б. Берелсон). В это время труды затрагивали разнородный и строго частотный анализ содержания понятий, работу с базовыми процедурами количественного контентанализа. Второй период (1940-1950-е гг.) - так называемый классический контент-анализ, когда проводились исследования речей официальных лиц. В ходе третьего этапа (1960-1970-е гг.) была разработана программа «Универсальный анализатор» и усовершенствована методика анализа [23-25]. В это же время начали публиковать исследования теоретического и методологического характера в области контент-анализа. Среди наиболее значимых работ советских исследователей следует отметить труды периода 1970-х гг. [26, 27] и 1980-х гг. [28, 29]. Со временем применение персональных компьютеров получило широкое распространение (четвертый этап, конец 1970-х гг. - по настоящее время), в результате возникли различные программы для компьютеризированного контент-анализа, которые постоянно совершенствуются. Опыт исследования исторических источников с помощью компьютеризированного контент-анализа насчитывает значительное число работ [30-34], однако в них авторы не анализировали программу MAXQDA. Кроме того, все практические исследования проводились с использованием материалов периодической печати или стенограмм официальных мероприятий. Отечественный исследователь Н.В. Раздина в нескольких публикациях продемонстрировала опыт применения программы MAXQDA для анализа материалов газеты «За индустриализацию» [35]. В связи с тем что опыт конкретного использования компьютерной программы MAXQDA в исторических работах не так многообразен, мы предлагаем рассмотреть возможности использования данной программы применительно к различным типам исторических источников, объединенных в сборнике документов «Магнитогорск довоенный».

История Советского Союза немыслима без изучения периода форсированной индустриализации и роли так называемого маленького человека. Магнитогорск город, созданный в период первых пятилеток, - олицетворяет собой форсированные темпы развития, ударный труд и энтузиазм, сложнейшие социально-бытовые условия. Магнитогорск во многом был уникален в рамках Урала и Советского Союза в целом. Во-первых, особое географическое положение (горожане живут в Европе, а на работу ездят в Азию) [36]; во-вторых, богатая природно-сырьевая база; в-третьих, Магнитогорск был в полном смысле слова «новым городом», не связанным с прошлым [37]; в-четвертых, строительство города и завода по объему капиталовложений превосходило все иные проекты индустриальной эпохи; впятых, только Магнитогорск стал завершенным проек- том - был полностью возведен металлургический завод с замкнутым производственным циклом и отстроен город. В научной литературе неоднократно подчеркивался мобилизационный характер сталинских преобразований. Изучение опыта мобилизации населения в 1930-е гг. представляет интерес в контексте исследования моральных и материальных стимулов к труду. В условиях латентного голода, социально-бытовой неустроенности, тяжелого физического труда магнитогорцы ежедневно совершали трудовой подвиг. Не вызывает сомнения, что одним из источников самоотверженного труда была грамотная пропаганда, в том числе и средствами периодической печати. Последняя выступала основой идеологопропагандистских кампаний. «Магнитогорский рабочий», «Магнитогорский металл», «Магнитогорский комсомолец», «Борьба за металл» и иные периодические издания Магнитостроя формировали определенные убеждения и ориентиры в поведении рядовых граждан. Официальная делопроизводственная документация, не ставила цели идеологического воспитания и пропаганды. Однако именно в процессе обсуждения текущих проблем руководство города и металлургического завода формировало методы воздействия на население, оценивало их эффективность и т.д. Кроме того, именно из документов, не предназначенных для огласки в средствах массовой информации, можно почерпнуть сведения о реальном положении вещей в городе.

Целью статьи являлось изучение функциональных возможностей программы MAXQDA в исторических исследованиях. Базой для анализа в программе MAXQDA стал сборник документов «Магнитогорск довоенный», опубликованный в 2010 г. Он включает материалы местной периодической печати (ежедневная городская газета «Магнитогорский рабочий», «Магнитогорский металл», «Магнитогорский комсомолец», «Борьба за металл» и другие многотиражные издания), неопубликованные архивные материалы (протоколы, стенограммы, планы и отчеты), почерпнутые в центральных, региональных и местных архивах, а также фрагменты эго-источников, принадлежащих участникам строительства города и завода. Тематика публикаций охватывает ключевые сферы жизни города и горожан в период с 1929 по 1941 г.: общие вопросы строительства города; производственную сферу - промышленные товары и товары широкого потребления; местную кооперативную и пищевую промышленность; городское благоустройство и жилье; здравоохранение; образование; снабжение и питание горожан; политическую сферу. В контексте каждого тематического блока возникали сюжеты об ударном труде и методах интенсификации производства, о роли партии и правительства в достижении высоких результатов и пр. При этом в сборник не включены документы, касающиеся металлургического завода. Авторы-составители сборника документов посчитали необходимым акцентировать внимание на незаслуженно обойденной краеведами и 
историками теме города и горожан, их проблем и переживаний. Каждый тематический раздел включает материалы как из газетных публикаций, так и из фондов архива, что позволяет понимать разницу в подаче информации между тем, что было в действительности и что хотели показать. Подобная широкая выборка материалов позволила наиболее объективно проанализировать процессы, протекавшие в городе в период индустриализации.

В ходе работы над материалом были исключены публикации за 1929 и 1941 гг., так как оба этих года представлены не полностью (первые рабочие на строительную площадку прибыли в марте 1929 г., а массово приезжать строители стали с ноября 1929 г.; в июне 1941 г. началась Великая Отечественная война, которая внесла существенные изменения в жизнь города и градообразующего предприятия). В целом автором статьи были проанализированы 424 документа, общий объем которых составил около 60 тысяч слов.

Ключевым методом изучения материалов сборника документов стал контент-анализ. Это особый инструмент исследования, представляющий собой единство количественного и качественного подходов к изучению исторического источника. В тексте статьи описан опыт работы с компьютерной программой MAXQDA. Программа MAXQDA, созданная немецкими учеными в 1989 г., быстро стала популярной и заслужила положительную репутацию в мире исследований методом контент-анализа. Инструменты программы дают возможность проводить комплексный анализ текста, а его результаты отражать в различных форматах в зависимости от целей и задач конкретного исследования. Также программа дает возможность получать графическое представление результатов исследования.

Анализ материалов сборника документов «Магнитогорск довоенный» был проведен с помощью бес- платной демоверсии MAXQDA 12, доступной на официальном сайте программы [38]. Работа с программой проводилась в следующих направлениях:

1) компьютеризованный анализ частот встречаемости слов, содержащихся в текстах;

2) подсчет частоты встречаемости смысловых категорий на основе заданных слов, выявленных на предыдущем этапе исследования;

3) изучение контекста в материалах сборника при упоминании слов, частота использования которых наиболее высока, что дало возможность уточнить, какие из сюжетов наиболее близки по своему содержанию.

Предварительным этапом компьютеризованного анализа материалов сборника стало создание списка «стоп-слов», не вошедшего в дальнейшие операции. «Стоп-слова» - это набор слов, который мог негативно повлиять на результаты исследования ввиду отсутствия в них необходимой смысловой нагрузки. В этот список были включены служебные части речи (междометия, местоимения, предлоги, союзы) и ряд других слов, которые, по субъективной оценке автора, не отражали особые черты времени и процессов, характерных для Магнитостроя. Таким образом, из 60 тысяч слов, которые содержались в сборнике документов, были исключены порядка 17 тысяч слов, не вошедших в сформированный список.

Подсчет частот встречаемости слов в сборнике был представлен в виде «облаков тэгов»: графического представления частот встречаемости наиболее значимых слов в тексте, размер шрифта которых зависел от степени их актуальности в данном массиве текстов. «Облака тэгов» были созданы в целом за период с 1930 по 1940 г. (рис. 1) и по каждому году в отдельности (рис. 2), а также в виде диаграммы (рис. 3).

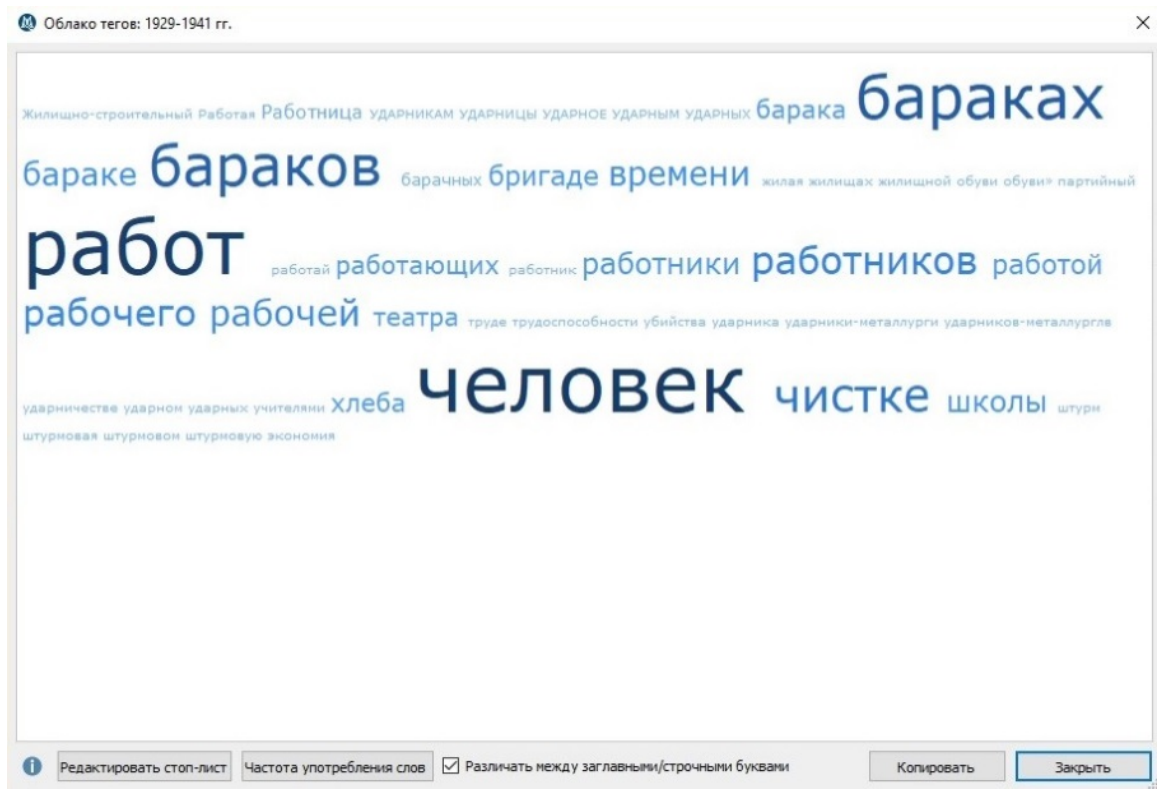

Рис. 1. Облако тегов. 1929-1941 гг. 

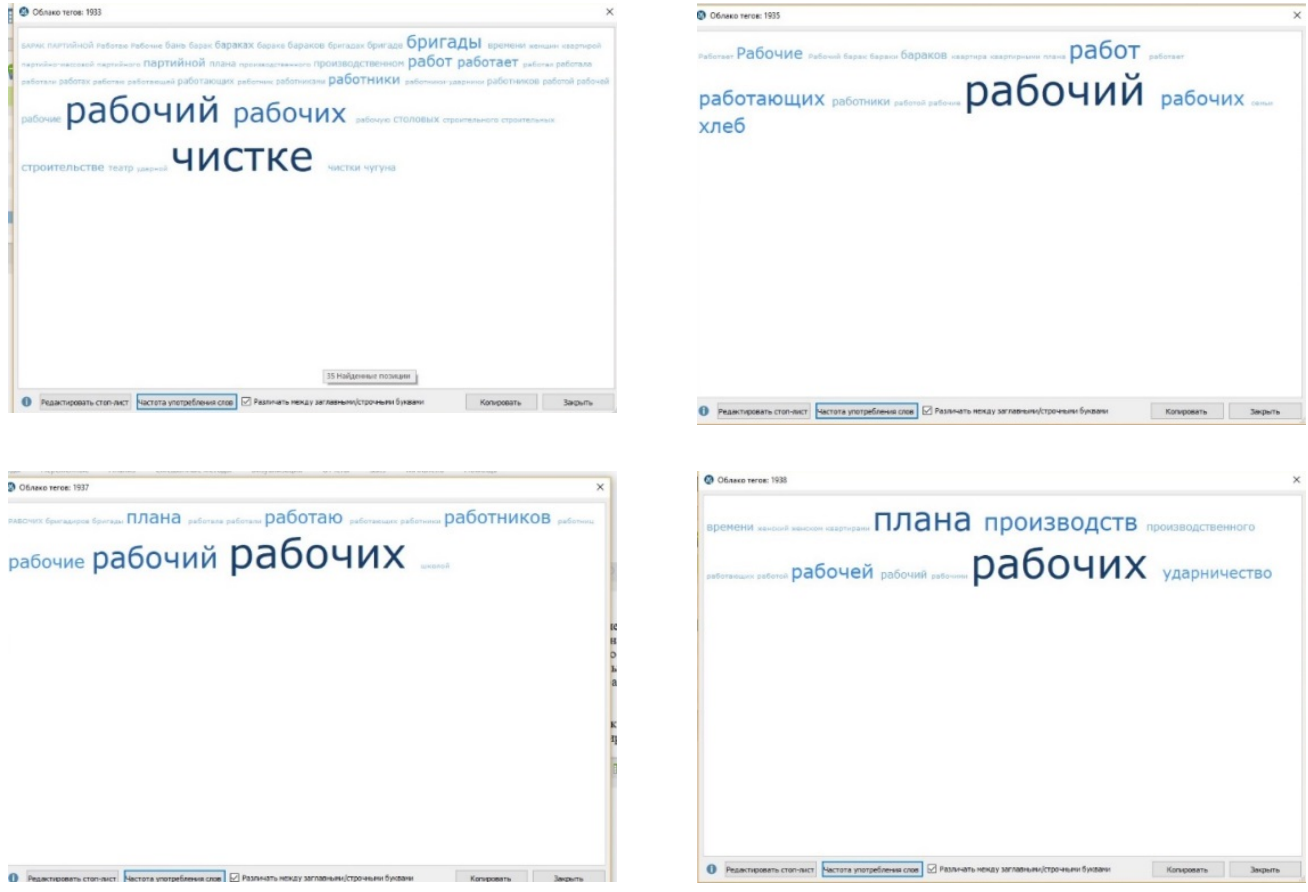

Рис. 2. Облако тегов за отдельные годы

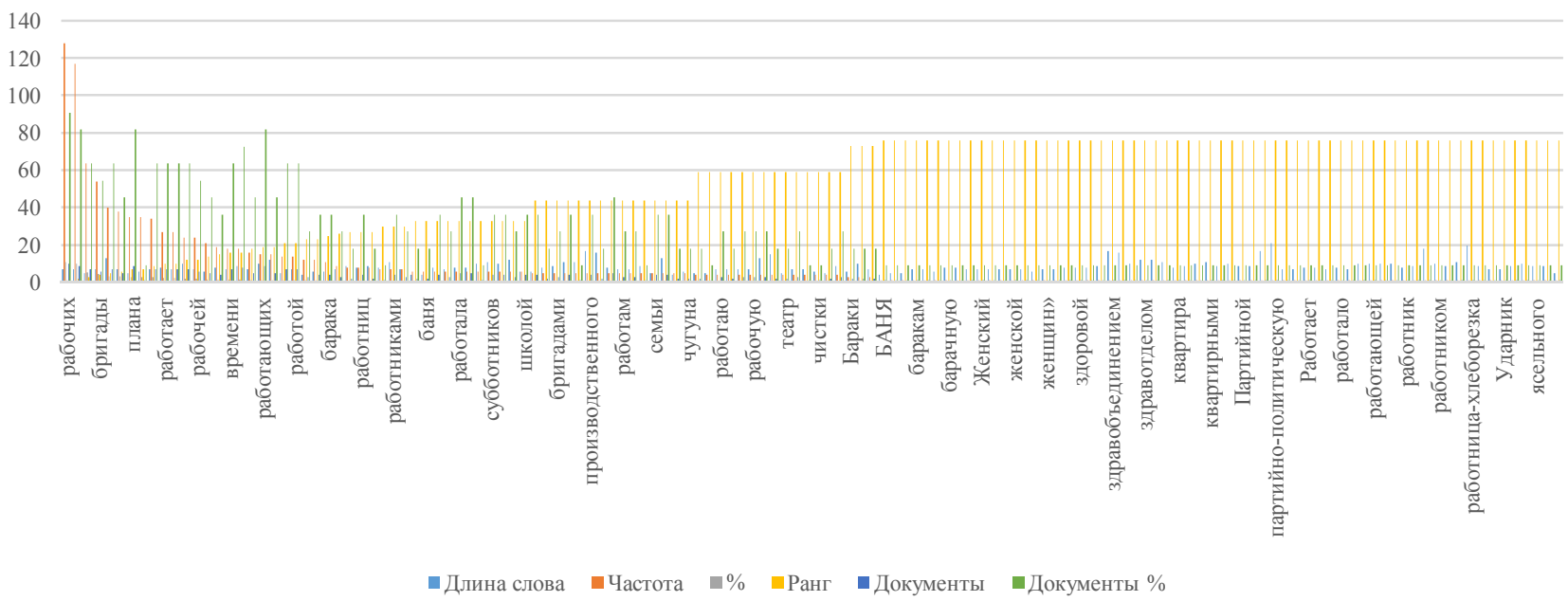

Рис. 3. Анализ частоты употребления слов в сборнике документов

В частности, в 1930 г. наиболее популярными словами были «работ», «рабочих», «работница», «план», «субботник», «женщина». В данном ряду слова перечислены в порядке убывания частоты использования в материалах сборника. Очевидно, что в 1930 г. первоочередными задачами Магнитостроя были поиск новой рабочей силы, в том числе и среди женского населения, и выполнение планов за счет непрерывной трудовой деятельности и проведения субботников. 1931 г. ознаменовался словами «рабочих», «бригада» «барак», «строительство». Этот набор слов вполне реалистично отражает ключевые вопросы Магнитостроя в данное время: возникновение острого жилищного кризиса и массовое строительство барачных конструкций. В 1932 г. к классическому набору слов добавляются «бригада», «баня», «столовая», «партия». Именно в
1932 г. в городе зарегестрирован пик эпидемических заболеваний, борьбу с которыми наряду со здравотделом города вела партия. Кроме того, в 1932 г. в Магнитогорске искали новые формы организации труда, отсюда - популярность слова «бригада». 1933 г. популяризировал слово «чистка», что объяснимо общесоюзными кампаниями партийных чисток. Среди наиболее популярных слов 1935 г. было существительное «Хлеб»; это связано с началом свободной торговли товарами первой необходимости и прежде всего хлебом. Наиболее стабильными словами, употреблявшимися как в газетных, так и в архивных документах за 19301940-е гг., были слова и их однокоренные формы от терминов «рабочий», «строительство», «ударный». Интересно, что слово «время» регулярно встречалось в этот период в документах сборника. Его логично свя- 
зать с темпами строительства города и металлургического завода, строительством объектов социальной инфраструктуры (больниц, школ, яслей, магазинов).

C помощью программы MAXQDA был реализован подсчет частоты встречаемости смысловых категорий материалов сборника документов. Данная процедура была реализована на основе конкретно заданных слов и терминов, характеризующих содержание выделенных категорий, но в рамках того списка категорий, который был сформирован в ходе предшествующего опыта работы с данным сборником. Определение смысловых категорий материалов подразумевало внимательное прочтение текста и дальнейшую его разбивку на информационные блоки (категории) с последующим подсчетом. Таким образом, после прочтения всей выборки автором было выделено семь общих категорий, описывающих все возможные темы сборника документов (табл. 1).

Смысловые категории сборника документов «Магнитогорск довоенный»

\begin{tabular}{|c|l|}
\hline $\begin{array}{c}\text { № кате- } \\
\text { гории }\end{array}$ & \multicolumn{1}{|c|}{ Смысловая категория } \\
\hline 1 & Новый человек \\
\hline 2 & Снабжение \\
\hline 3 & Барачный быт \\
\hline 4 & Здравоохранение \\
\hline 5 & Образование \\
\hline 6 & Строительство объектов первоочередного значения \\
\hline 7 & Социалистическое соревнование \\
\hline
\end{tabular}

Смысловые категории анализа охватывали разные стороны жизни Магнитогорска. Все перечисленные категории сосуществовали на протяжении периода с 1930 по 1940 г. Однако популярность указанных смысловых категорий менялась. Так, вопросы здравоохранения и образования были наиболее популярными в период превышения эпидемического порога в городе (по отношению к категории № 4) и переполненности школ, низкого уровня обученности (по отношению к категории № 5). Категория «новый человек», связанная с идеологическим воспитанием в городе и формированием должного социального поведения, была представлена в материалах сборника документов постоянно. Аналогичное положение в публикациях имела категория «социалистическое соревнование», которая включает не только форму соцсоревнования, но и все формы перевыполнения планов и достижение успехов в труде. Практически каждый документ сборника тесно связан с двумя и более категориями одновременно. Объем содержания категории менялся от одного предложения до фрагмента текста (абзаца).

Очередной этап работы с программой состоял в формировании списка слов-индикаторов, характеризующих содержание каждой категории (табл. 2). На основе этого списка были произведены запросы о частоте встречаемости единиц подсчета. К примеру, категория «новый человек» определялась следующими словами: «город», «возможность», «борьба», «партия», «быт», «женщина», категория «социалистическое соревнование» - словами «рекорд», «ударник», «соревнование», «труд», «работник». Выбор именно этих индикаторов был обусловлен спецификой содержания каждой смысловой категории и субъективными представлениями автора о содержании материалов сборника, которое сложилось в ходе многократного прочтения текстов и их соотношения с определенными смысловыми блоками. В целом слова-индикаторы, приведенные в табл. 2, были расценены автором как наиболее типичные и уникальные для каждой из выделенных категорий.

Смысловые категории и слова-индикаторы Т а б ли ц а 2 сборника документов «Магнитогорск довоенный»

\begin{tabular}{|c|l|l|}
\hline $\begin{array}{c}\text { № кате- } \\
\text { гории }\end{array}$ & Смысловая категория & \multicolumn{1}{|c|}{ Слова-индикаторы } \\
\hline 1 & Новый человек & $\begin{array}{l}\text { Город, равенство, возможности, } \\
\text { культурный быт, борьба, партия, } \\
\text { женщина }\end{array}$ \\
\hline 2 & Снабжение & $\begin{array}{l}\text { Хлеб, столовые, питание, карточ- } \\
\text { ки, дефицит, распределение }\end{array}$ \\
\hline 3 & Барачный быт & $\begin{array}{l}\text { Барак, ремонт, антисанитария, } \\
\text { скученность, жилье }\end{array}$ \\
\hline 4 & Здравоохранение & $\begin{array}{l}\text { Медицина, врач, санитарная } \\
\text { обстановка, болезнь, смерть }\end{array}$ \\
\hline 5 & Образование & $\begin{array}{l}\text { Школа, учитель, ученик, обуче- } \\
\text { ние, ликбез, рабфак }\end{array}$ \\
\hline 6 & $\begin{array}{l}\text { Строительство объек- } \\
\text { тов первоочередного } \\
\text { значения }\end{array}$ & $\begin{array}{l}\text { План, металлургический завод, } \\
\text { время, партия }\end{array}$ \\
\hline 7 & $\begin{array}{l}\text { Социалистическое } \\
\text { соревнование }\end{array}$ & $\begin{array}{l}\text { Рекорд, соревнование, ударник, } \\
\text { удабничество, ударный труд, } \\
\text { работник }\end{array}$ \\
\hline
\end{tabular}

С помощью интерактивного дерева слов слова и словосочетания могут быть изучены и проанализированы визуально в соответствующих контекстах. Чем чаще встречается слово или словосочетание, тем отчетливее оно появляется в дереве. Дерево предлагает двустороннюю интерактивность: во-первых, его можно перемещать по отдельным «ветвям», чтобы визуализировать слова в их контексте. Во-вторых, данные интерактивно связаны с оригинальными текстами, так что у автора была возможность просматривать слова и фразы в MAXQDA в «браузере документов». Данные функциональные возможности позволили осуществить визуальную поддержку исследования и соотнести значимые слова (часто встречающиеся) с контекстом всех документов.

Структура интерактивного дерева выглядит следующим образом. Само дерево отражено на левой панели экрана. Правая область содержит исходные тексты, выстроенные в нашем случае в хронологическом порядке. Дерево выстраивается согласно следующей логике: самое часто используемое слово «в» показано слева (рис. 4). Оно образует корень дерева слов. Следующее наиболее часто употребляемое слово после корневого слова отображается правее. На данном рисунке это слова «частности» и «результате». Согласно этой логике каждая ветвь дерева растет дальше, пока 
остается только одна фраза. Стоп-слова в интерактивном дереве не применяются, чтобы избежать нарушения потока чтения. Видимая часть дерева слов демонстрируется в области отображения. Количество отображаемых ветвей с различными текстовыми строками показана на верхней панели инструментов. Если ветвей больше, чем места, отображается число видимых ветвей, за которым следует общее число ветвей в скобках. В приведенном выше примере видны 43 из 1600 ветвей. Подсказка, которая появляется при наведении курсора мыши на слово, показывает, как часто это слово отображается в анализируемых текстах. Из рис. 4 видно, что слово «квартале» фигурирует в материалах сборника документов 16 раз.

Автор исследования использовал самые популярные слова, отобранные в ходе первого этапа компьютеризированного анализа и слова-индикаторы, выявленные в по- следующей работе для формирования интерактивного дерева. Результаты компьютеризованного контентанализа материалов сборника «Магнитогорск довоенный» позволили сформулировать следующие выводы. Вопервых, развитие г. Магнитогорск, нашедшее отражение на страницах сборника документов в 1930-е гг., было неразрывно связано со строительством и эксплуатацией металлургического завода. Даже при условии отсутствия в сборнике документов, касающихся ММК прямо, связь города и завода, человека и производства очевидна.

Во-вторых, издание отражает широкий спектр тем из жизни города и горожан в период форсированной индустриализации, а следовательно, первоисточники (архивные документы и газетные публикации) не были зациклены на какой-то одной проблеме. Самой популярной темой этих лет оказалась тема труда и строительства (рис. 5).

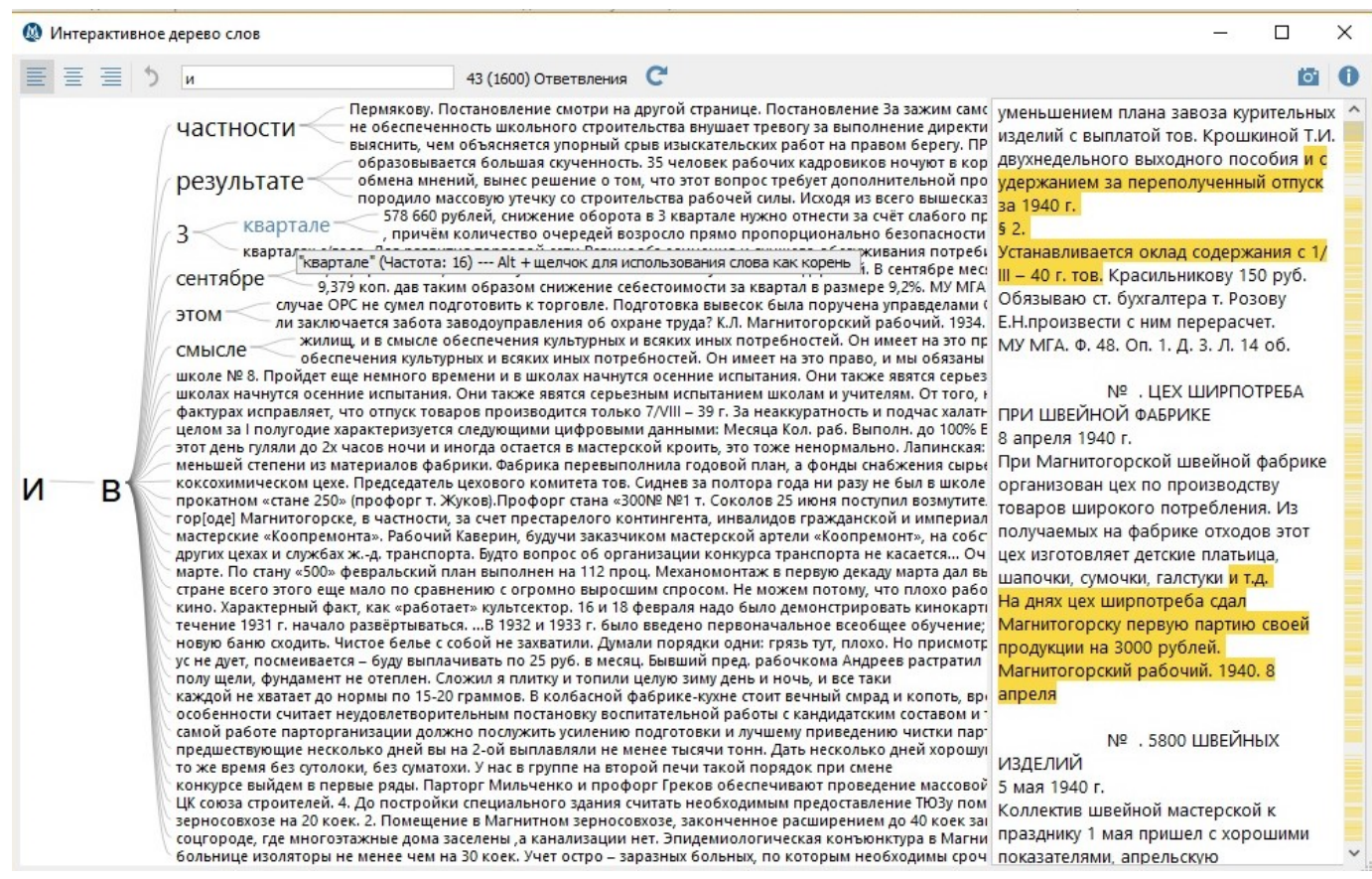

Рис. 4. Интерактивное дерево слов
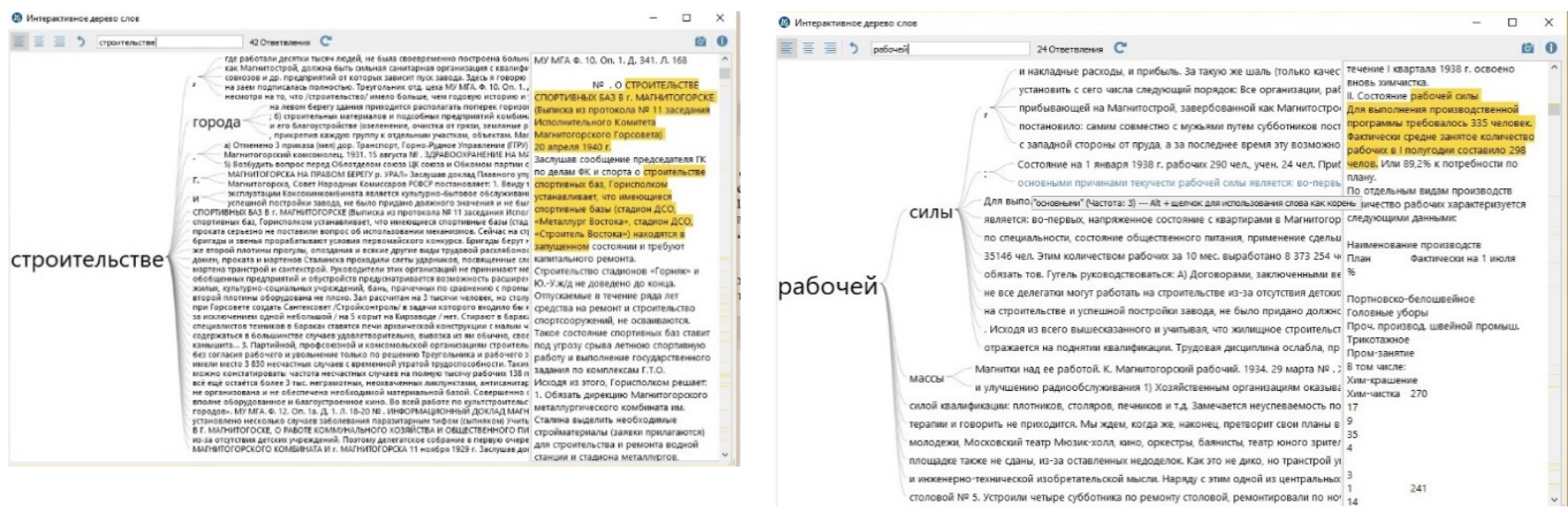

Рис. 5. Интерактивное дерево к словам «строительстве» и «рабочей»

Как уже было отмечено раннее, текст одного документа мог быть соотнесен сразу с несколькими категориями (как правило, с двумя или тремя). Одной из главных задач данного исследования было установить степень взаимосвязей этих категорий между собой. $\mathrm{C}$ помощью программы MAXQDA удалось определить 
их совместную встречаемость в рамках одного фрагмента (в данном случае - предложения). Результаты этого сравнения представлены на рис. 6. Совместная частота встречаемости смысловых категорий материалов сборника наглядно оказывает основные тенденции жизни горожан и создания города и завода. Так, категория «новый человек» чаще пересекается с категориями «образование», «барачный быт» и «социалистическое строительство», отражая цели культурной революции и требования партии и правительства в отношении формирования образа города в границах СССР и за его пределами. Категория «барачный быт» наиболее тесно связана с качеством здравоохранения и темпами строительства.

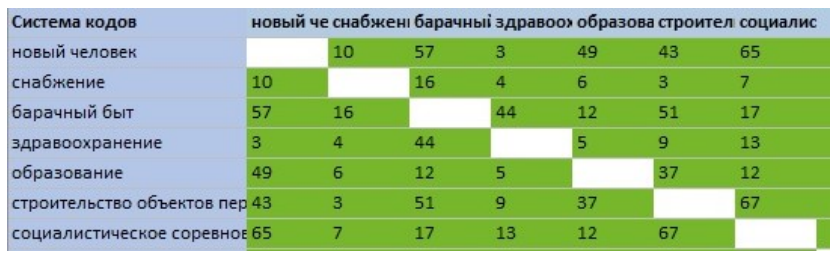

Рис. 6. Совместная встречаемость смысловых категорий в рамках фрагмента

В целом объем работ, проведенных на примере сборника «Магнитогорск довоенный» средствами MAXQDA, позволил сделать следующие выводы. Вопервых, программа создает преимущественные условия для работы исследователя с большими объемами информации. Он не затрачивает большие объемы времени и усилий для подсчета частоты упоминания слов в тексте источника. Все операции программа выполняет мгновенно, отображая результаты статистики в таблицах формата exel (их можно сохранять как в пакете проекта программы, так на жестком диске компьютера). Отсутствует опасность неточности при подсчете слов в тексте. Наиболее трудоемкой по времени стадией работы с программой выступает составление списка «стоп-слов», так как требуется проверка вручную смысловых нагрузок всех терминов, отраженных в отчете программы. Во-вторых, возможности программы позволяют получить новые сведения, которые недоступны для исследователя, использующего традиционные инструменты и методы работы с источником (например, подсчет частоты встречаемости слов в каж- дый временной отрезок и установление взаимосвязей между категориями). В-третьих, исследование сборника материалов с помощью MAXQDA позволило визуализировать информацию. В рамках подготовки презентаций для выступлений на конференциях или иллюстративных рядов для публикаций это огромное преимущество. В-четвертых, программа может работать с источником на любом языке и с разнообразными форматами предоставления информации (rtf, txt, PDF, аудио- и видеофайлы). Именно эта особенность программы MAXQDA позволяет историку работать с большими объемами источников, ранее не оцифрованных (сохраняя материалы, например, в формате PDF). Программа также позволяет создавать отчеты, готовые для печати или отправки по электронной почте.

Метод контент-анализа, довольно хорошо известный в историческом сообществе, благодаря программе становится более удобным в применении и выступает эффективным способом извлечения неявной информации в источнике, дополняя традиционные методы исторических исследований. Контент-анализ, изначально созданный для работы с периодической печатью, применим для анализа разнообразных видов источников исторической информации средствами MAXQDA. Данная программа предлагает возможность не просто формального анализа текстов, но и способна производить факторный анализ лексем, выделенных при первичной обработке текста. Это дает возможность идентифицировать лексически и тематически фрагменты текстов, определить основные и частные «сюжеты». В конечном итоге это обеспечивает более глубокий и многомерный контент-анализ. Разнообразные нарративные документы, рассмотренные в качестве примера в нашей статье, отличаются разнообразием, широкими хронологическими рамками, большим объемом информации и в результате становятся равноправным материалом для исторической информатики. Компьютеризированный контент-анализ исторических текстов находит собственное место среди методов источниковедения, а программа MAXQDA является перспективным средством для крупных источниковедческих и историографических исследований, в том числе в русле истории повседневности, истории эмоций, визуальной истории и пр.

\section{ЛИТЕРАТУРА}

1. Володин А.Ю. Digital Humanities (цифровые гуманитарные науки): в поисках самоопределения // Вестник Пермского университета. Сер. История. 2014. № 3 (26). С. 5-12.

2. Ayers E.L. The Pasts and Futures of Digital Hstory (Online Essy). 1999. URL: http://www.vcdh.virginia.edu/PastsFutures.html (дата обращения: 15.12.2017).

3. Cohen D., Rosenzweig R. Digital History: A Guide to Gathering, Preserving, and Presenting the Past on the Web. University of Pennsylvania Press, 2002. 316 p.

4. Бородкин Л.И. Историческая информатика в развитии: методологические аспекты // Круг идей: модели и технологии исторической информатики / под ред. Л.И. Бородкин, В.С. Тяжельникова. М., 1996. С. 16-21.

5. Бородкин Л.И. Историк в мире компьютерных технологий: развитие по спирали? // Электронный научно-образовательный журнал «История». 2015. T. 6, вып. 8 (41). URL: http://history.jes.su/s207987840001263-8-1, доступ для зарегистрированных пользователей (дата обращения: 04.10.2017). DOI: 10.18254/S0001263-8-1

6. Бородкин Л.И. Digital history: применение цифровых медиа в сохранении историкокультурного наследия? // Историческая информатика. 2012. № 1. C. 14-21. 
7. Бородкин Л.И. Историческая информатика в точке бифуркации: движение к Historical Information Science // Круг идей: алгоритмы и технологии исторической информатики / под ред. Л.И. Бородкина, В.Н. Владимирова. Москва ; Барнаул, 2005. С. 7-21.

8. Можаева Г.В. Digital Humanities: цифровой поворот в гуманитарных науках // Гуманитарная информатика. 2015. № 9. С. 8-23.

9. Можаева Г.В., Можаева-Ренья П.Н., Сербин В.А. Цифровая гуманитаристика: организационные формы и инфраструктура исследований // Вестник Томского государственного университета. 2014. № 389. С. 73-81.

10. Alkhoven P., Doorn P. New Research Perspectives for the Humanities // International Journalof Humanities and Arts Computing. 2007. Vol. 1, № 1. P. 35-47.

11. Boonstra O., Breure L., Doorn P. Past, Present and Future of Historical Information Science. Amsterdam : IWI-KNAW, 2004. 130 p.

12. Гарскова И. М. Информационное обеспечение гуманитарных исследований в цифровую эпоху: модели формирования и развития // Вестник Пермского университета. Серия «История». 2014. № 3 (26). С. 76-86.

13. Гарскова И.М. Новые тенденции развития исторической информатики: по материалам конференций 2000-х гг. // Вестник ЧелГУ. История. 2011. № 9. С. 144-153.

14. Таллер М. Дискуссии вокруг Digital Humanities // Историческая информатика. 2012. № 1. C. 5-13.

15. Кижнер И.А., Рудов И.Н., Румянцев М.В., Хлебопрос Р.Г. Конференция Digital Humanities 2016: перспективы и вызовы для развития сообщества гуманитарной информатики // Электронный научно-образовательный журнал «История». 2016. T. 7, вып. 7 (51). URL: http:/history.jes.su/s207987840001676-2-1, доступ для зарегистрированных пользователей (дата обращения: 04.10.2017). DOI: $10.18254 / \mathrm{S} 0001676-2-1$

16. Дегтярев А.Я., Кащенко С.Г., Раскин Д.И. Методика применения ЭВМ в изучении реформы 1861 г. // Количественные методы в гуманитарных науках. М. : МГУ, 1981. С. 60-71.

17. Дробижев В.З., Соколов А.К., Устинов В.А. Рабочий класс Советской России в первый год пролетарской диктатуры (Опыт структурного анализа материалов профессиональной переписи 1918 г.). М. : Изд-во Моск. ун-та, 1974. 224 с.

18. Кащенко С.Г. Применение компьютеров при комплексном изучении дел Главного выкупного учреждения // Комплексные методы в исторических исследованиях. М. : Наука, 1987. С. 37-45.

19. Киселев И.Н., Мироненко С.В. Социальный портрет высшей бюрократии первой четверти ХІХ в. Количественный анализ // Комплексные методы в изучении истории с древнейших времен до наших дней. М., 1984. С. 175-176.

20. Жеребятьев Д.И. Методы трехмерного компьютерного моделирования в задачах исторической реконструкции монастырских комплексов Москвы. М. : МАКС Пресс, 2014. 222 с.

21. Бородкин Л.И. Моделирование исторических процессов: от реконструкции реальности к анализу альтернатив. СПб. : Алетейя, 2016.304 с.

22. Гусева Н.С. Применение математических методов в исследованиях по аграрной истории России пореформенного и советского периодов: историографические аспекты проблемы (1960-е - начало 1990-х гг.) // Вестник Томского государственного университета. История. 2017. № 46. С. $155-162$.

23. Литвак Б.Г. О некоторых приемах публикации источников статистического характера // Исторический архив. 1957. № 2. С. 155-166.

24. Дробижев В.З. Методы статистической обработки протоколов ВСНХ (1917-1929 гг.) // Вестник МГУ. Сер. 8. История. 1965. № 6. С. 70-92.

25. Ковальченко И.Д. О применении математических методов при анализе историко-статистических данных // История СССР. 1964 . № 1. С. $13-20$.

26. Здравомыслов А.Г. Возможности использования контент-анализа для построения теоретической концепции (на примере изучения проблемы управления) // Методологические и методические проблемы контент-анализа. М. ; Л. : ИСИ АН СССР, 1973. Вып. І. С. $40-45$.

27. Количественные методы в гуманитарных науках / под ред. И.Д. Ковальченко. М. : Изд-во МГУ, 1981.357 с.

28. Бородкин Л.И. Многомерный статистический анализ в исторических исследованиях. М. : Изд-во МГУ, 1986.187 с.

29. Carney T.F. Content Analysis. A Review Essay in Historical Methods // Newsletter. 1971. № 4. P. 52-61.

30. Holsti O. Content Analysis for Social Science and Humanities Research. Reading. Mass. Addison-Wesley, 1969. 235 p.

31. Merritt R.L. The Emergence of American Nationalism. A Quantitative Approach // American Quarterly. 1965. P. $319-335$.

32. Olsen M. The Language of Enlightened Politics. The Societe de 1789 in the French Revolution // Computer and the Humanities. 1989. № 23. P. 357364.

33. Weber R. Basic Content Analysis. Newbury Park. Calif, 1990. 95 p.

34. Раздина Н.В. Газета «За индустриализацию» как источник для изучения промышленной политики советского государства в 1930-е гг. (опыт работы с программой MAXQDA) // Электронный научно-образовательный журнал «История». 2015. T. 6, вып. 8 (41). URL: http://history.jes.su/s207987840001230-2-1, доступ для зарегистрированных пользователей (дата обращения: 04.10.2017). DOI: $10.18254 / \mathrm{S} 0001230-2-1$

35. Макарова Н.Н. «В котле индустриализации»: повседневная жизнь Магнитогорска в 1929-1941 гг. Магнитогорск, 2014.432 с.

36. Макарова Н.Н. «Новый человек» на Магнитострое: повседневность и мотивация труда // Проблемы российской истории. 2015. С. $115-127$.

37. MAXQDA. Программное обеспечение для качественных и смешанных исследований. URL: http://www.maxqda.com/, свободный (дата обращения: 23.02.2018)

Nadezhda N. Makarova. Nosov Magnitogorsk State Technical University (Magnitogorsk, Russian Federation). E-mail: makarovanadia@mail.ru

A COLLECTION OF DOCUMENTS "MAGNITOGORSK PREWAR" AS A SOURCE FOR STUDYING THE HISTORY OF INDUSTRIALIZATION (EXPERIENCE WITH THE PROGRAM MAXQDA)

Key words: industrialization, Magnitogorsk, text analysis, content analysis, the first five-year plan, MAXQDA.

In recent years, "digital history" or "historical informatics" are gaining popularity in the world and Russian historical science. This is due to the accumulation of new types of historical sources and the need for their storage and analysis, as well as the wide spread of information technology. Historical science, traditionally, working with collections of libraries and archives during the 1980's and 2000's was actively involved in the achievements of the "digital humanities". Among the leading researches in the field of digital history it is necessary to note the works of A.Yu. Volodin, L.I. Borodkin, G.V. Mojaeva, M. Thaler, I.M. Garskova, P. Alkoven, P. Doorn, O. Boonstra, L. Breure. Significant works in the field of study of the content analysis are the study of A.I. Alekseev, A.G. Zdravomyslova, I.D. Koval'chenko, L.I. Borodkina, M. Olsen, R.L. Merritt. Despite the presence of a significant number of studies in the field of "digital history", publications that demonstrate specific experience in the use of digital technology in history based on the program MAXQDA have not been distributed. This article describes the experience of content analysis of the materials of the collection of documents "Magnitogorsk prewar". The object of the study was made by a computer program MAXQDA and its capabilities under specific historical research. The collection "Magnitogorsk prewar" includes both materials of the local periodicals (for example, the daily city newspaper "Magnitogorsk worker", the city newspaper "Magnitogorsk metal" and a number of local multi-page publications) and unpublished archival documents (protocols, transcripts, plans and reports), selected in the Central, regional and local archives, as well as the materials of ego-documents. The computer program MAXQDA, created in 1989 by German scientists, provides a more in-depth and multidimensional content analysis. Various narrative documents, considered as an example in this paper, differ in diversity, broad 
chronological framework, a large amount of information and as a result become equal materials for historical informatics. The use of this program, as one of the leading in the field of complex analysis of the text, made it possible to obtain accurate data on the characteristics of the development of the city of Magnitogorsk during the period of forced industrialization (1930-1940) by year, the links between the content of articles and some general information about the language of publications in these years. The author showed a specific method of working with a historical source using the MAXQDA program (counting the frequency of word usage, working with tag clouds, the use of an interactive tree, the definition of semantic categories, the study of the context of the collection of documents in relation to indicator words, etc.). The obtained results allow to supplement the idea of the processes of industrial development of Magnitogorsk, as well as to visualize the main trends reflected in the source material.

\section{REFERENCES}

1. Volodin, A.Yu. (2014) Digital Humanities (tsifrovye gumanitarnye nauki): v poiskakh samoopredeleniya [Digital Humanities: in search of selfdetermination]. Vestnik Permskogo universiteta. Seriya "Istoriya"-Perm University Herald. History. 3(26). pp. 5-12.

2. Ayers, E.L. (1999) The Pasts and Futures of Digital Hstory. [Online] Available from: http://www.vcdh.virginia.edu/PastsFutures.html (Accessed: 15th December 2017)

3. Cohen, D. \& Rosenzweig, R. (2002) Digital History: A Guide to Gathering, Preserving, and Presenting the Past on the Web. Pennsylvania: University of Pennsylvania Press.

4. Borodkin, L.I. (1996) Istoricheskaya informatika v razvitii: metodologicheskie aspekty [Historical information science in development: methodological aspects]. In: Borodkin, L.I. \& Tyazhel'nikova, V.S. (eds) Krug idey: modeli i tekhnologii istoricheskoy informatiki [The circle of ideas: algorithms and technologies of historical Informatics]. Moscow: Moscow State University. pp. 16-21.

5. Borodkin, L.I. (2015) Istorik v mire komp'yuternykh tekhnologiy: razvitie po spirali? [Historian in the world of computer technology: the development of a spiral?]. Istoriya. 8(41). [Online] Available from: http://history.jes.su/s207987840001263-8-1 (Accessed: 4th October 2017). DOI: $10.18254 / \mathrm{S} 0001263-8-1$

6. Borodkin, L.I. (2012) Digital History: Application of Digital Media in Preservation of Historical-Cultural Heritage? Istoricheskaya informatika - Historical Information Science. 1. pp. 14-21. (In Russian).

7. Borodkin, L.I. (2005) Istoricheskaya informatika $v$ tochke bifurkatsii: dvizhenie k Historical Information Science [Historical information science at the bifurcation point: the movement to Historical Information Science]. In: Borodkin, L.I. \& Vladimirov, V.N.(eds) Krug idey: algoritmy i tekhnologii istoricheskoy informatiki [The circle of ideas: algorithms and technologies of historical informatics]. Moscow; Barnaul: [s.n.]. pp. 7-21.

8. Mozhaeva, G.V. (2015) Digital Humanities: digital turn in the humanities. Gumanitarnaya informatika - Humanitarian Informatics. 9. pp. 8-23. (In Russian)

9. Mozhaeva, G.V., Mozhaeva-Renya, P.N. \& Serbin, V.A. (2014) Digital Humanities: organizational forms and infrastructure research. Vestnik Tomskogo gosudarstvennogo universiteta - Tomsk State University Journal. 389. pp. 73-81. (In Russian). DOI: 10.17223/15617793/389/10

10. Alkhoven, P. \& Doorn, P. (2007) New Research Perspectives for the Humanities. International Journal of Humanities and Arts Computing. 1(1). pp. 35-47.

11. Boonstra, O., Breure, L. \& Doorn, P. (2004) Past, Present and Future of Historical Information Science. Amsterdam: IWI-KNAW.

12. Garskova, I.M. (2014) Informatsionnoe obespechenie gumanitarnykh issledovaniy v tsifrovuyu epokhu: modeli formirovaniya i razvitiya [Information support of Humanities research in the digital age: a model of formation and development]. Vestnik Permskogo universiteta. Seriya "Istoriya”-Perm State University Herlad. History. 3(26). pp. 76-86.

13. Garskova, I.M. (2011) Novye tendentsii razvitiya istoricheskoy informatiki: po materialam konferentsiy 2000-kh gg. [New trends in the development of historical informatics: conference proceedings of the 2000s]. Vestnik ChelGU. Istoriya. 9. pp. 144-153.

14. Taller, M. (2012) Controversies around the Digital Humanities. Istoricheskaya informatika - Historical Information Science. 1. pp. 5-13. (In Russian).

15. Kizhner, I.A., Rudov, I.N., Rumyantsev, M.V. \& Khlebopros, R.G. (2016) Konferentsiya Digital Humanities 2016: perspektivy i vyzovy dlya razvitiya soobshchestva gumanitarnoy informatiki [The conference Digital Humanities 2016: prospects and challenges for community development of humanitarian informatics]. Istoriya. 7(51). [Online] Available from: http://history.jes.su/s207987840001676-2-1 (Accessed: 4th October 2017). DOI: 10.18254/S0001676-2-1

16. Degtyarev, A.Ya., Kashchenko, S.G. \& Raskin, D.I. (1981) Metodika primeneniya EVM v izuchenii reformy 1861 g. [Methods of use of computers to study the Reform of 1861]. In: Kovalchenko, I.D. (ed.) Kolichestvennye metody v gumanitarnykh naukakh [Quantitative Methods in the Humanities]. Moscow: Moscow State University. pp. 60-71.

17. Drobizhev, V.Z., Sokolov, A.K. \& Ustinov, V.A. (1974) Rabochiy klass Sovetskoy Rossii v pervyy god proletarskoy diktatury (Opyt strukturnogo analiza materialov professional'noy perepisi $1918 \mathrm{~g}$.) [The working class of Soviet Russia in the first year of the proletarian dictatorship (the structural analysis of materials occupational census in 1918)]. Moscow: Moscow State University.

18. Kashchenko, S.G. (1987) Primenenie komp'yuterov pri kompleksnom izuchenii del Glavnogo vykupnogo uchrezhdeniya [The use of computers in the comprehensive study of the Main Redemption Institution]. In: Kompleksnye metody $v$ istoricheskikh issledovaniyakh [Integrated Methods in Historical Research]. Moscow: Nauk. pp. 37-45.

19. Kiselev, I.N. \& Mironenko, S.V. (1984) Sotsial'nyy portret vysshey byurokratii pervoy chetverti XIX. Kolichestvennyy analiz [Social portrait of the highest bureaucracy of the first quarter of the 19th century. Quantitative analysis]. In: Kompleksnye metody v izuchenii istorii s drevneyshikh vremen do nashikh dney [Complex methods in the study of history from ancient times to the present day]. Moscow. pp. 175-176.

20. Zherebyatiev, D.I. (2014) Metody trekhmernogo komp'yuternogo modelirovaniya v zadachakh istoricheskoy rekonstruktsii monastyrskikh kompleksov Moskvy [Methods of three-dimensional computer modeling in the problems of historical reconstruction of the monastery complexes of Moscow]. Moscow: MAKS Press.

21. Borodkin, L.I. (2016) Modelirovanie istoricheskikh protsessov: ot rekonstruktsii real'nosti $k$ analizu al'ternativ [Modeling of historical processes: from the reconstruction of reality to the analysis of alternatives]. St. Petersburg: Aleteyya.

22. Guseva, N.S. (2017) Application of mathematical methods in researches on the Russian agrarian history of the post-reform and Soviet periods: historiographical aspects of the problem (the 1960s - the beginning of the 1990s). Vestnik Tomskogo gosudarstvennogo universiteta. Seriya Istoriya Tomsk State University Journal of History. 46. pp. 155-162. (In Russian). DOI: 10.17223/19988613/46/20

23. Litvak, B.G. (1957) O nekotorykh priemakh publikatsii istochnikov statisticheskogo kharaktera [About some methods of publication of statistical sources]. Istoricheskiy arkhiv. 2. pp. 155-166.

24. Drobizhev, V.Z. (1965) Metody statisticheskoy obrabotki protokolov VSNKh (1917-1929 gg.) [Methods of statistical processing of the protocols of the Supreme Economic Council (1917-1929)]. Vesti. MGU. Ser. 8. Istoriya. 6. pp. 70-92.

25. Kovalchenko, I.D. (1964) O primenenii matematicheskikh metodov pri analize istoriko-statisticheskikh dannykh [On the application of mathematical methods in the analysis of historical and statistical data]. Istoriya SSSR. 1. pp. 13-20.

26. Alekseev, A.I. (1970) Nekotorye problemy sotsiologicheskogo izucheniya massovoy kommunikatsii [Some problems of the sociological study of mass communication]. Novosibirsk: [s.n.]. 
27. Zdravomyslov, A.G. (1973) Vozmozhnosti ispol'zovaniya kontent-analiza dlya postroeniya teoreticheskoy kontseptsii (na primere izucheniya problemy upravleniya) [Possibilities of using content analysis to build a theoretical concept (using the example of studying the management problem)]. In: Metodologicheskie i metodicheskie problemy kontent-analiza [Methodological problems of content analysis]. Issue I. Moscow; Leningrad: USSR AS. pp. $40-45$.

28. Kovalchenko, I.D. (1981) Kolichestvennye metody v gumanitarnykh naukakh [Quantitative methods in the Humanities]. Moscow: Moscow State University.

29. Borodkin, L.I. (1986) Mnogomernyy statisticheskiy analiz v istoricheskikh issledovaniyakh [Multivariate statistical analysis in historical research]. Moscow: Moscow State University.

30. Carney, T.F. (1971) Content Analysis. A Review Essay in Historical Methods. Newsletter. 4. pp. 52-61.

31. Holsti, O. (1969) Content Analysis for Social Science and Humanities Research. Reading. Mass.: Addison-Wesley.

32. Merritt, R.L. (1965) The Emergence of American Nationalism. A Quantitative Approach. American Quarterly. pp. 319-335.

33. Olsen, M. (1989) The Language of Enlightened Politics. The Societe de 1789 in the French Revolution. Computer and the Humanities. 23. pp. 357364. DOI: $10.1007 / \mathrm{BF} 02176641$

34. Weber, R. (1990) Basic Content Analysis. Newbury Park. Calif.

35. Razdina, N.V. (2015) Gazeta "Za industrializatsiyu" kak istochnik dlya izucheniya promyshlennoy politiki sovetskogo gosudarstva v 1930-e gg. (opyt raboty s programmoy MAXQDA) [Newspaper "Za industrializatsiyu" as a Source for the Study of Industrial Policy Soviet state in the 1930s (a case with MAXQDA)]. Istoriya. 8(41). [Online] Available from: http://history.jes.su/s207987840001230-2-1 (Accessed: 4th October 2017). DOI: $10.18254 / \mathrm{S} 0001230-2-1$

36. Makarova, N.N. (2014) “V kotle industrializatsii”: povsednevnaya zhizn' Magnitogorska v 1929 - 1941 gg. ["In the cauldron of industrialization": the daily life of Magnitogorsk in 1929-1941]. Magnitogorsk: [s.n.].

37. Makarova, N.N. (2015) "Novyy chelovek" na Magnitostroe: povsednevnost' i motivatsiya truda ["New Man" in Magnitostroy: Everyday life and labor motivation]. Problemy rossiyskoy istorii. pp. 115-127.

38. MAXQDA. Software for quality and mixed research. [Online] Available from: http://www.maxqda.com/ (Accessed: 23rd February 2018). 